\title{
Role of Bismuth and Substrate Temperature on the Optical Properties of Some Flash Evaporated $\mathrm{Se}_{100-\mathrm{x}} \mathrm{Bi}_{\mathrm{x}}$ Glassy System
}

\author{
Austine A. Mulama ${ }^{1,2}{ }^{*}$, Julius M. Mwabora ${ }^{2}$, Andrew O. Oduor ${ }^{1}$, Cosmas M. Muiva ${ }^{3}$, \\ Boniface Muthoka ${ }^{2}$, Betty N. Amukayia ${ }^{1}$, Drinold A. Mbete ${ }^{4}$ \\ ${ }^{1}$ Department of Physics \& Materials Science, Maseno University, Maseno, Kenya \\ ${ }^{2}$ Department of Physics, University of Nairobi, Nairobi, Kenya \\ ${ }^{3}$ Department of Physics, Botswana International University of Science \& Technology, Palapye, Botswana \\ ${ }^{4}$ Department of Mathematics, Masinde Muliro University of Science and Technology, Kakamega, Kenya \\ Email: ${ }^{*}$ mulamaustine@gmail.com
}

Received 28 February 2015; accepted 21 March 2015; published 25 March 2015

Copyright (C) 2015 by authors and Scientific Research Publishing Inc.

This work is licensed under the Creative Commons Attribution International License (CC BY).

http://creativecommons.org/licenses/by/4.0/

(c) (i) Open Access

\begin{abstract}
Chalcogenide glasses are very important in the modern technology especially selenium-based. These glasses are sensitive to electromagnetic radiation useful in the infrared optics. The study investigated the effect of substrate temperature on the as-deposited selenium-bismuth thin films in addition to bismuth content. The films were deposited by flash evaporation method. Thickness of the films was measured on a surface profiler and confirmed through calculation based on the Swanepoel method. The spectral range of study was between $200-3000 \mathrm{~nm}$. It is found that the effect of increasing bismuth content on the as-deposited films led to increased absorption coefficient, reflectance, refractive index and extinction coefficient while transmittance and optical band gap energy decreased. On the other hand, reflectance, absorption coefficient, extinction coefficient, refractive index, real and imaginary parts of dielectric constant increased with increase in substrate temperature but transmittance and optical band gap energy decreased.
\end{abstract}

\section{Keywords}

Chalcogenide Glass, Selenium-Bismuth Alloy, Substrate Temperature

\section{Introduction}

Sulphur, selenium, and tellurium from group 6 of the periodic table, combine with other elements like germa-

"Corresponding author.

How to cite this paper: Mulama, A.A., Mwabora, J.M., Oduor, A.O., Muiva, C.M., Muthoka, B., Amukayia, B.N. and Mbete, D.A. (2015) Role of Bismuth and Substrate Temperature on the Optical Properties of Some Flash Evaporated $\mathrm{Se}_{100-\mathrm{x}} \mathrm{Bi}_{\mathrm{x}}$ Glassy System. New Journal of Glass and Ceramics, 5, 16-24. http://dx.doi.org/10.4236/njgc.2015.52003 
nium, antimony, lead, gallium, among others, to form chalcogenide glasses [1]. These glasses are rigid materials whose structures lack crystalline periodicity or long-range order. Information on the short-range order structure of chalcogenide glasses is particularly valuable in order to establish useful correlations between their structural and microscopic properties. Chalcogenide glasses are future prospective materials which would provide less expensive technical devices in the field of optoelectronics, owing to their versatile thermo-physical, optical, midinfrared and electrical properties [2]. The area of selenium-based chalcogenide glasses is still growing and open for investigation. Amorphous selenium-based chalcogenides have the unique property of reversible transformation, making these alloys useful in optical memory device formation [3]. Pure amorphous selenium is unstable and less sensitive to electromagnetic radiation in standard operational conditions because its glass transition temperature (about $42^{\circ} \mathrm{C}$ ) is close to room temperature putting it in perpetual danger of crystallization [4]. In order to stabilize these glasses, it is common to add certain additives which act as cross-linking agents and increase the dimensionality of structure and stability of the selenium chalcogenide glass. The glass transition temperature of stabilized selenium is about $70^{\circ} \mathrm{C}[5]$.

The role of bismuth in affecting the optical properties of the glasses of amorphous selenium system in addition to substrate temperature has been investigated. There is limited literature on the effect of substrate temperature on the optical properties of the as-deposited Se-Bi thin films. Addition of bismuth to selenium films is said to increase the stability, sensitivity of the films and changes the carrier type [6]. Bismuth on the order of about 0.5 to 5.0 atomic percent in combination with selenium has been found to be sensitive in the infrared region [7].

\section{Experimental Details}

Glassy alloys of $\mathrm{Se}_{100-\mathrm{x}} \mathrm{Bi}_{\mathrm{x}}(\mathrm{x}=0,2$, and 4 at. \%) were prepared by normal melt quenching technique under evacuated quartz ampoules (Edwards AUTO 306 Vacuum system, UK). The sealed ampoules were kept in a rotatable programmable furnace where the temperature was raised to $900^{\circ} \mathrm{C}$ at a rate of $4^{\circ} \mathrm{C}$ per minute and maintained at this temperature for 12 hours to ensure complete melting and homogenization of the mixture. This temperature was chosen because chalcogenide glasses belong to substances which have incongruent melting points and exhibit high partial vapour pressures during melting.

Selenium vapours with the main constituents of $\mathrm{Se}_{6}$ and $\mathrm{Se}_{5}$ molecules remain at nearly constant concentration at about $730^{\circ} \mathrm{C}$ [8]. The ampoules were quenched by removing them from the furnace at the highest temperature and dropping in ice cold water to form amorphous bulk samples. The rate at which the temperature was raised of $4^{\circ} \mathrm{C}$ per minute ensured that there was no sudden build up of pressure in the ampoules. The ampoules were broken to obtain the solid alloy that was crushed into powder for flash evaporation under vacuum (Edwards AUTO 306 Vacuum system, UK). The optimum substrate-source distance was predetermined to be $11 \mathrm{~cm}$. The substrate temperatures were: $51^{\circ} \mathrm{C}, 55^{\circ} \mathrm{C}$, and $59^{\circ} \mathrm{C}$. The deposition rate was $1000 \mathrm{As}^{-1}$.

The amorphous nature of the deposited films was verified by X-Ray Diffraction machine (Phillips PW3710, UK). Film thickness was measured using a computerized KLA-Tencor Alpha-Step IQ surface profiler whose resolution was $0.01 \mu \mathrm{m}$ (KLA-Tencor Corporation, USA). Hence, the measured thickness was $350 \pm 10 \mathrm{~nm}$. The thickness calculated based on Swanepoel method was within $\pm 10 \mathrm{~nm}$ from that obtained from the surface profiler. Transmittance and reflectance measurements were measured on a SolidSpec.3700 DUV, UV-VIS-NIR Spectrophotometer (SolidSpec.3700 DUV, Kyoto-Japan). The optical transmission spectra in the wavelength range $200 \mathrm{~nm}-3000 \mathrm{~nm}$ have been used to calculate the optical parameters in the amorphous thin films of $\mathrm{Se}_{100-\mathrm{x}} \mathrm{Bi}_{\mathrm{x}}$.

For maximum transmission [9]:

$$
T=\exp -(\alpha d)
$$

where $d$ is the film thickness

The absorption coefficient $(\alpha)$ and extinction coefficient $(k)$ are related by the following expression [10];

$$
\alpha=4 \pi k / \lambda,
$$

where $\lambda$ is the wavelength

Refractive index, real and imaginary parts of dielectric constant and the indirect allowed optical band gap energy were determined from the following expressions [11]-[13]:

$$
n=\left[N+\left(N^{2}-n_{s}^{2}\right)^{1 / 2}\right]^{1 / 2}
$$


where $N=2 n_{s}\left(T_{M}-T_{m}\right) / T_{M} T_{m}+\left(n_{s}^{2}+1\right) / 2$, and $T_{M}, T_{m}$, are the maximum and minimum transmittance envelope functions respectively, $n_{s}$ is the substrate refractive index

$$
\varepsilon_{1}=n^{2}-k^{2} ; \quad \varepsilon_{2}=2 n k,
$$

where $\varepsilon_{1}, \varepsilon_{2}$ are the real and imaginary parts of the dielectric constant

The band gap energy was calculated using the following expression;

$$
\alpha h v=\beta\left(h v-E_{g}\right)^{2}
$$

where $\alpha$ is the absorption coefficient, $\beta$ is a constant, $h v$ is the photon energy, and $E_{g}$ is the optical band gap energy.

If $n_{1}$ and $n_{2}$ are the refractive indices at two adjacent maxima (or minima) at $\lambda_{1}$ and $\lambda_{2}$ (Wavelengths), then the film thickness is determined according to [11]:

$$
d=\lambda_{1} \lambda_{2} / 2\left(\lambda_{1} n_{2}-\lambda_{2} n_{1}\right)
$$

\section{Results and Discussion}

Results on the flash evaporated $\mathrm{Se}_{100-\mathrm{x}} \mathrm{Bi}_{\mathrm{x}}(\mathrm{x}=0,2$, and 4 at. \%) thin films deposited on glass substrates at temperatures of $51^{\circ} \mathrm{C}, 55^{\circ} \mathrm{C}$, and $59^{\circ} \mathrm{C}$ and whose thickness is $350 \pm 10 \mathrm{~nm}$ are presented. The substrate temperature is slightly above the maximum temperature for the ratio of chains and rings in the amorphous selenium to be at balance, which is usually at $50^{\circ} \mathrm{C}$ [8] [14]. Amorphous selenium films prepared at a substrate temperature of about $65^{\circ} \mathrm{C}$ may have enough vibrational energy to break some weak bonds. This leads to translational degrees of freedom, making the system to change from amorphous to polycrystalline state [14].

\subsection{Results}

Calculated film thicknesses according to Equation (2.6) [11] are given in Table 1. The values agree with that obtained from the surface profiler.

Transmittance and reflectance of the as-deposited thin films at substrate temperatures of $51^{\circ} \mathrm{C}, 55^{\circ} \mathrm{C}$ and $59^{\circ} \mathrm{C}$ revealed that both transmittance (Figure 1(a)) and reflectance (Figure 1(b)) increased with increase in wave-

Table 1. Calculated values of film thickness from Swanepoel Method.

\begin{tabular}{cccccc} 
& $\lambda_{1} \mathrm{~nm}$ & $\lambda_{2} \mathrm{~nm}$ & $n_{1}$ & $n_{2}$ & $d \mathrm{~nm}$ \\
\hline$x=0$ & 800 & 603 & 2.726 & 2.922 & 348 \\
& 910 & 622 & 2.592 & 2.649 & 354 \\
& 1095 & 674 & 2.527 & 2.547 & 340 \\
& 1401 & 768 & 2.490 & 2.513 & 335 \\
& & & & $\bar{d}=344$ \\
& 980 & 667 & 2.775 & 2.874 & 338 \\
& 1085 & 699 & 2.669 & 2.720 & 349 \\
& 1255 & 749 & 2.537 & 2.611 & 341 \\
& 1609 & 847 & 2.362 & 2.480 & 342 \\
& & & & $\bar{d}=343$ \\
& 1107 & 736 & 2.862 & 2.960 & 348 \\
& 1211 & 766 & 2.682 & 2.784 & 352 \\
& 1504 & 827 & 2.522 & 2.607 & 339 \\
& 1718 & 868 & 2.395 & 2.474 & 343 \\
& & & & $\bar{d}=346$ \\
\hline
\end{tabular}



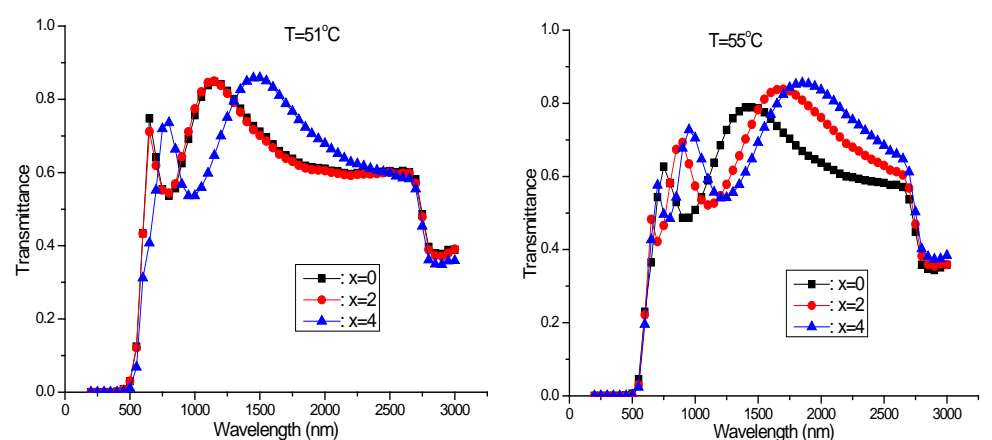

(a)
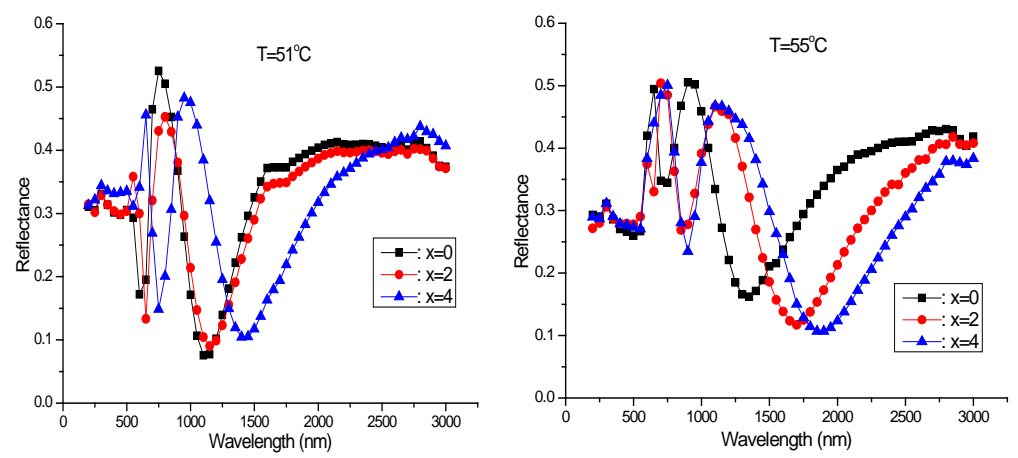

(b)
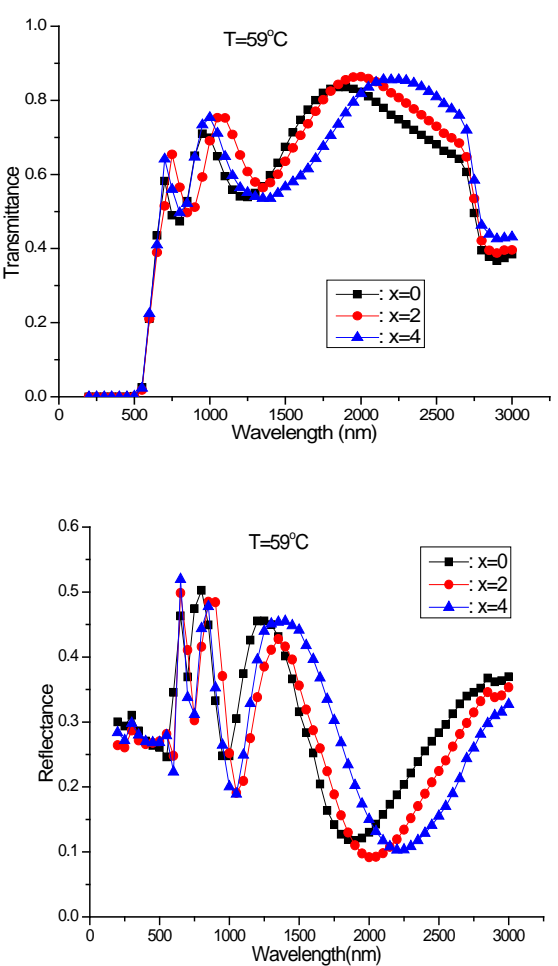

Figure 1. (a) Transmittance against wavelength at different substrate temperatures. (b) Reflectance against wavelength at different substrate temperatures.

length. There were interference patterns in the transmittance spectra. The transmittance was zero at low wavelengths (200 nm - $500 \mathrm{~nm})$.

The variation of absorption coefficient for the $350 \mathrm{~nm} \mathrm{Se}{ }_{100-x} \mathrm{Bi}_{x}$ thin films with photon energy grown at different substrate temperatures is displayed in Figure 2. It is observed that the absorption coefficient increases with increase in substrate temperature and bismuth content.

It is clear from Figure 3 that the extinction coefficient of the as-deposited thin films increases with increase in substrate temperature and bismuth content.

It is observed from Figure 4 that as the substrate temperature and bismuth content increased, the refractive index increased.

From Figure 5, it is observed that the graph of real part of dielectric constant against wavelength is similar to the graph of refractive index against wavelength.

The optical band gap energy, $E_{g}$ was determined from a plot of $(\alpha h v)^{1 / 2}\left(\mathrm{eVcm}^{-1}\right)^{1 / 2}$ against photon energy (eV) according to [15]. Other researchers have also found selenium rich binary and ternary glasses to obey the indirect rule transition [16] [17]. Indirect optical band gap energy from the studied thin films was observed to decrease with increase in substrate temperature and bismuth content as shown in Figure 6.

Figures 7(a)-(b) show an increase in reflectance, absorption coefficient, extinction coefficient, refractive index, real and imaginary parts of the dielectric constant and a decrease in the transmittance and optical band gap energy as substrate temperature increases.

The optical band gap energy $(\mathrm{eV})$ tabulated in Table $2(\lambda=700 \mathrm{~nm})$ is found to decrease as bismuth content and substrate temperature increase.

Figure 8 shows X-Ray Diffraction patterns of the $\mathrm{Se}_{100-x} \mathrm{Bi}_{\mathrm{x}}$ thin films of thickness $350 \pm 10 \mathrm{~nm}$. The figure revealed that the as-deposited films are amorphous in nature as no prominent peak was observed in their patterns. Absence of any sharp peaks in X-Ray Diffraction patterns confirmed the glassy nature of $\mathrm{Se}_{100-\mathrm{x}} \mathrm{Bi}_{\mathrm{x}}$ thin films [17]. This simply means that the grain size of the films was so small and that the disorder within these grains was so high that no specific diffraction peaks could be detected. The humps as observed in Figure 8 are the effect of the glass substrate as confirmed from the pattern of the blank glass substrate. Presence of humps in the 

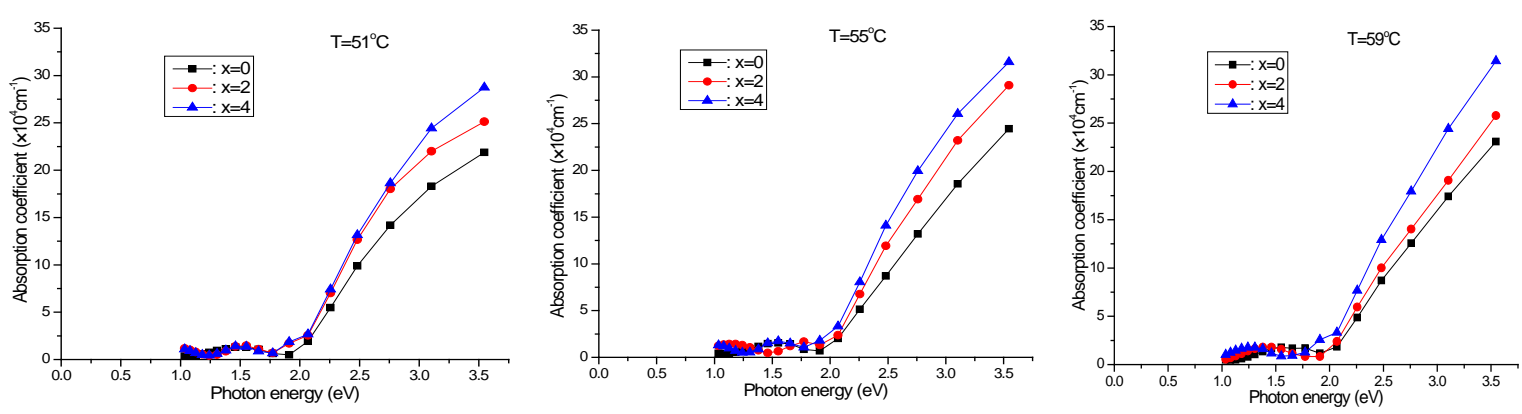

Figure 2. Absorption coefficient against photon energy at different substrate temperatures.
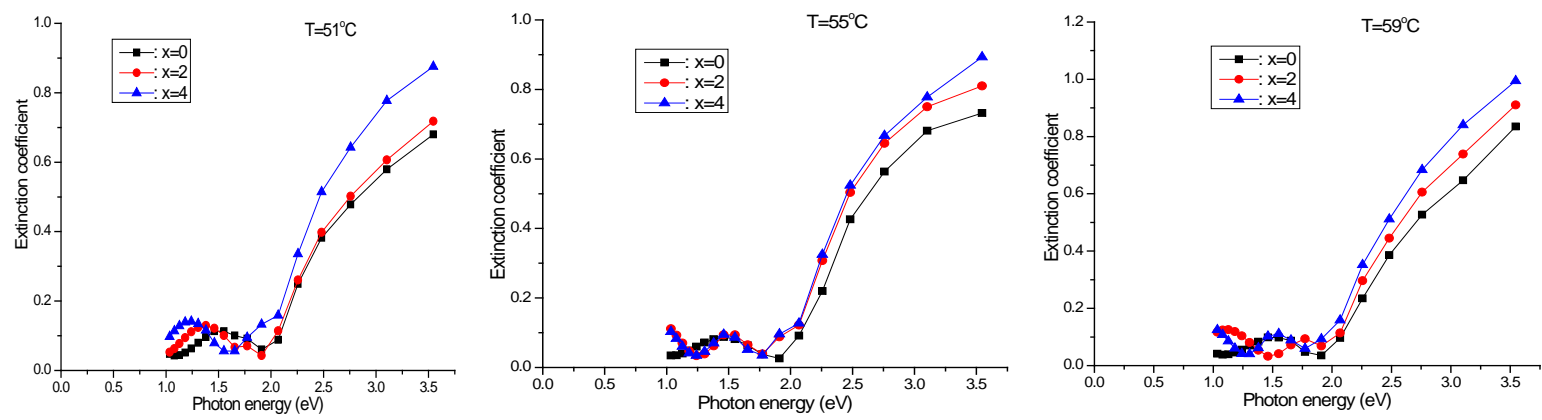

Figure 3. Extinction coefficient against photon energy at different substrate temperatures.
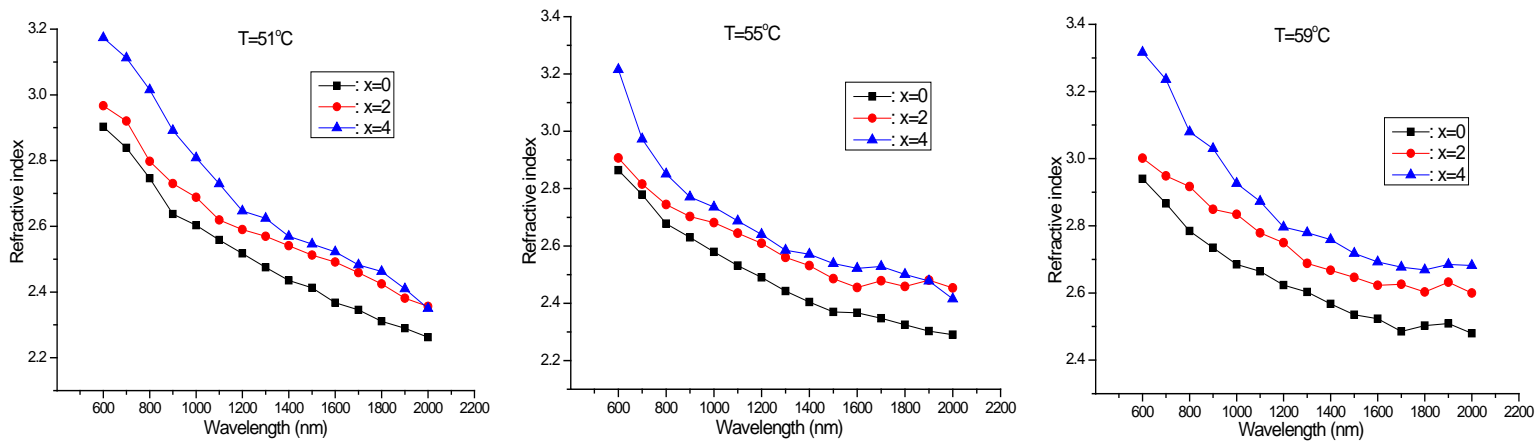

Figure 4. Refractive index against wavelength at different substrate temperatures.
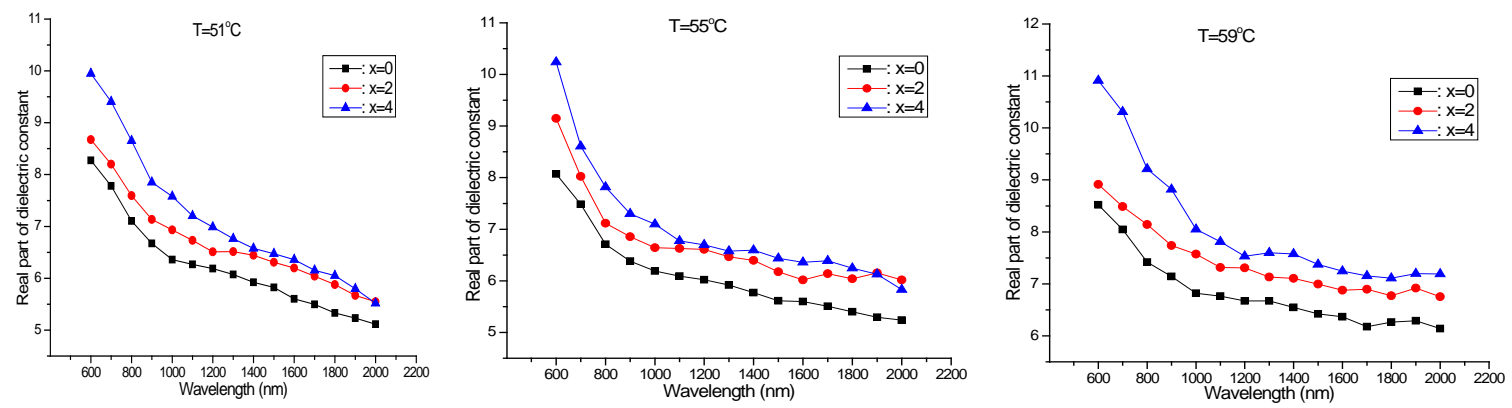

Figure 5. Real part of dielectric constant against wavelength at different substrate temperatures.

XRD patterns is verification of small to medium range order in amorphous thin films [18].

\subsection{Discussion}

The transmittance spectra of the as-deposited amorphous $\mathrm{Se}_{100-\mathrm{x}} \mathrm{Bi}_{\mathrm{x}}$ thin films exhibited oscillatory behavior 

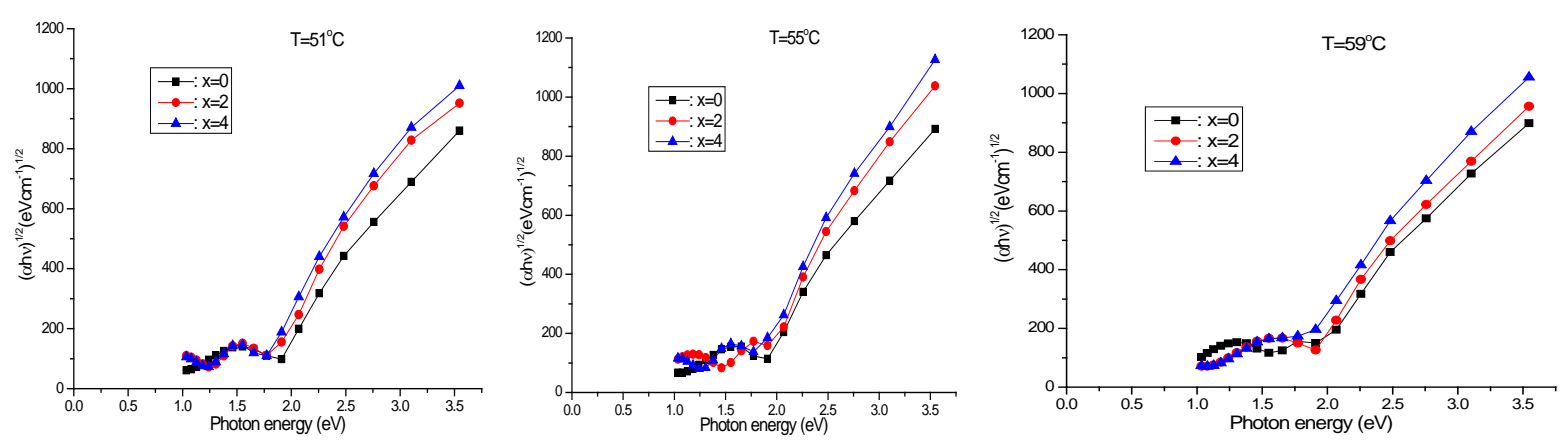

Figure 6. Energy gap against photon energy at different substrate temperature.

possibly due to interference patterns between the wave fronts reflected from the two surfaces of thin films. This was an indication of optical homogeneity of the deposited films [18]. The transmittance was zero in the lower wavelength region due to photon absorption. The transmittance of the as-deposited thin films decreased with the increase in bismuth concentration. This is due to defects introduced in the deposited films by the bismuth addition which led to increase in light absorption. Increase in substrate temperature from $51^{\circ} \mathrm{C}$ to $59^{\circ} \mathrm{C}$ led to decrease in transmittance at specific wavelengths especially in the visible region but reflectance increased. This trend has been observed by other authors while studying other chalcogenide thin films [17] [19]. The transmission spectra shifted towards the visible range on bismuth addition, showing an improvement in the photo-response of the system as observed from the reduced band gap energy. This is an indication of increase in absorption of light by the deposited films.

The increased absorption coefficient with bismuth addition and increased substrate temperature consequently implies reduction in transmittance of the films and also an indication of less transparent films. The values of the absorption coefficient are in the order of $10^{4} \mathrm{~cm}^{-1}$ and have been observed by other authors [19] [20]. Increase in extinction coefficient was due to the effect of absorption coefficient of the films. The general low values of extinction coefficient in the order of $10^{-2}$ in the visible region may be a qualitative indication of excellent surface smoothness of the $350 \mathrm{~nm} \mathrm{Se}_{100-x} \mathrm{Bi}_{x}$ thin films. This behavior of increase of extinction coefficient with substrate temperature is well correlated with low transmittance observed in the visible region at specific wavelengths.

Refractive index increased with increase in both bismuth content and substrate temperature. Increase in refractive index as the bismuth content increases may also be due to increased polarizability of the larger bismuth atoms compared to selenium atoms. The atomic radius of bismuth is $1.50 \AA$ and that of selenium is $1.20 \AA$ [21]. Since the atomic radius of bismuth is greater than that of selenium, its polarizability is higher than that of selenium according to Lorentz-Lorenz relation [22]:

$$
\left(n^{2}-1\right) /\left(n^{2}+2\right)=\frac{1}{3 \varepsilon_{o}}\left[\sum_{i} N_{i} \alpha_{p i}\right]
$$

where $\varepsilon_{o}$ is the vacuum permittivity, $N_{i}$ is the number of polarisable units of type $i$ per unit volume with polarizability, $\alpha_{p i}$

The increase of refractive index with substrate temperature may be due to narrowing of pores since the film surface gets denser as temperature of the substrate increases. The real part of the dielectric constant indicates the amount of light slowed down by the films and the imaginary part of the dielectric constant shows how a dielectric material absorbs energy from light. Both the real and imaginary parts of the dielectric constant increased with increase in bismuth content and substrate temperature. The values of real part of dielectric constant were greater than those for imaginary part which has also been observed by [17].

There was a decrease in optical band gap of $\mathrm{Se}_{100-x} \mathrm{Bi}_{x}$ thin films with substrate temperature and bismuth concentration. Substrate temperature may have induced modifications in the density of the unsaturated bonds because of insufficient number of atoms deposited in the amorphous films [14] [23]. The unsaturated bonds are responsible for the formation of gap states in the films that contribute to the effective spread in the localized states near the mobility edges. The presence of a high concentration of localized states is assumed to be responsible for the decrease in the optical band gap in the as-deposited thin films [24]. Decrease in optical band gap 

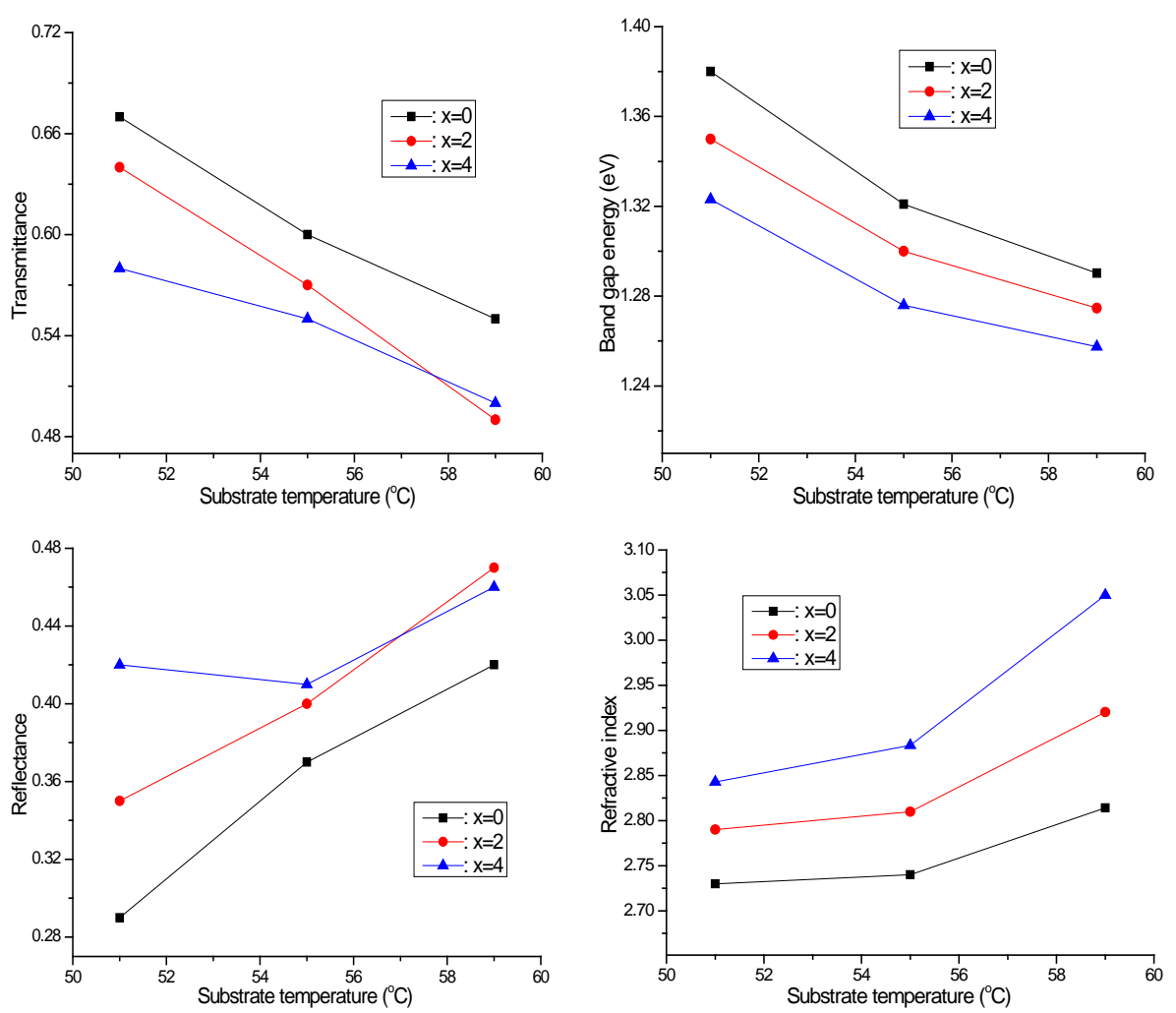

(a)
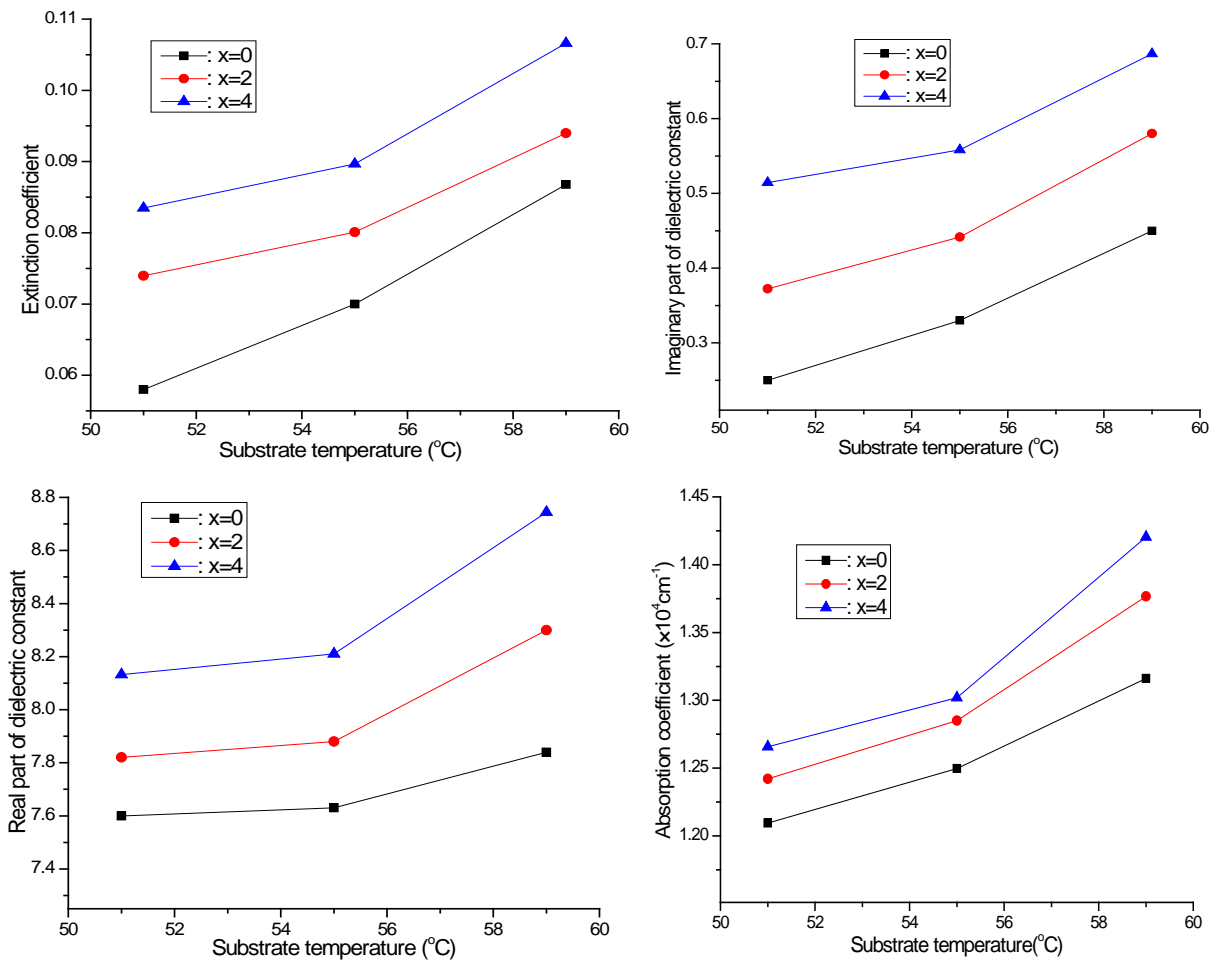

(b)

Figure 7. (a) Transmittance, band gap energy, reflectance, and refractive index against substrate temperature at $\lambda=700 \mathrm{~nm}$. (b) Extinction coefficient, absorption coefficient, real and imaginary parts of dielectric constant against substrate temperature at $\lambda=700 \mathrm{~nm}$. 


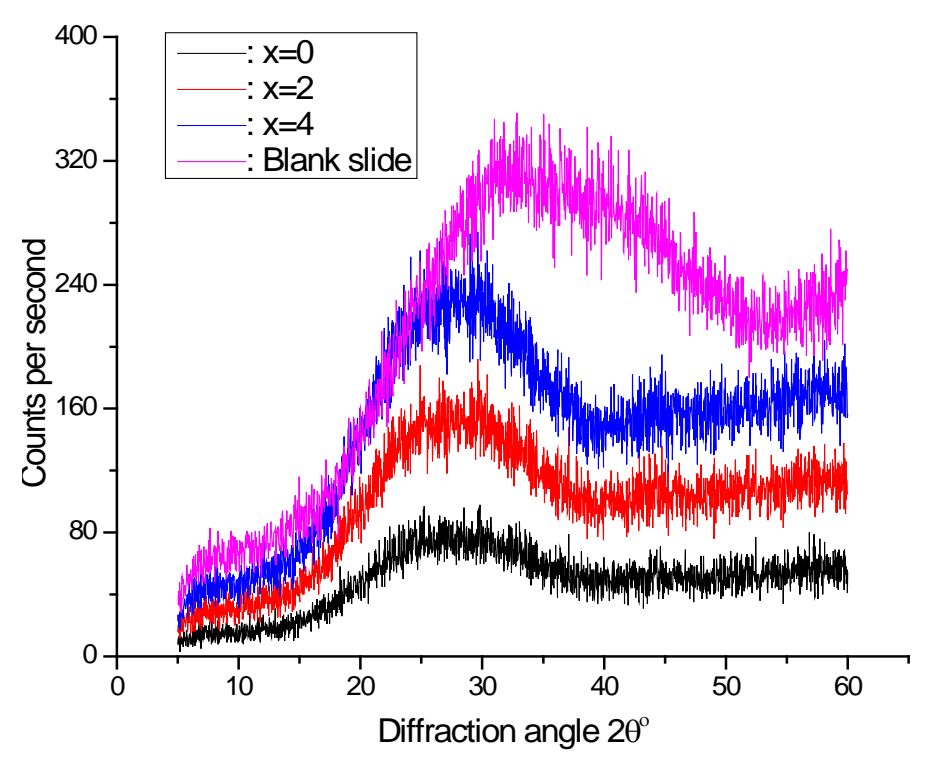

Figure 8. XRD patterns for the as-deposited films.

Table 2. Optical band gap (eV) of the as-deposited thin films.

\begin{tabular}{ccccc}
\hline Sub.tem./at.\% & $x=0$ & $x=2$ & $x=4$ \\
\hline $51^{\circ} \mathrm{C}$ & 1.681 & 1.625 & 1.626 \\
$55^{\circ} \mathrm{C}$ & 1.641 & 1.632 & 1.618 \\
$59^{\circ} \mathrm{C}$ & 1.625 & 1.611 & 1.593 \\
\hline
\end{tabular}

energy may also have been as a result of decrease in cohesive energy of the $\mathrm{Se}_{100-\mathrm{x}} \mathrm{Bi}_{\mathrm{x}}$ system due to bismuth addition [25].

\section{Conclusion}

Transmission of light in the as-deposited thin films decreased with increase in substrate temperature and bismuth content while the reflectance increased. The absorption coefficient increased with increase in substrate temperature and bismuth content. In addition, the as-deposited films seem to be more sensitive to light as bismuth concentration increases as observed from the shift in transmittance profiles towards the visible region. Hence, we can conclude that the deposited films' sensitivity to light increases with increase in substrate temperature and bismuth content. The extinction coefficient of the as-deposited films increased with increase in substrate temperature and bismuth content due to increased absorption coefficient of the as-deposited thin films. Refractive index of the as-deposited thin films obtained using the Swanepoel method, decreased with increase in wavelength but increased with increase in bismuth concentration and substrate temperature. The optical band gap energy decreased slightly with increase in bismuth content and substrate temperature. This has been explained in terms of decreased cohesive energy in the as-deposited amorphous thin films. The real and imaginary parts of dielectric constant increased with increase in bismuth concentration and substrate temperature.

\section{Acknowledgements}

The authors wish to thank the Kenya National Council for Science and Technology (Now National Commission for Science, Technology and Innovation (NACOSTI)) for the financial support (Grant No. 010545).

University of Nairobi provided the research equipment and the technical support.

\section{References}

[1] Mohd, N. and Zulfequar, M. (2012) DC Conductivity and Dielectric Behavior of Glassy Se ${ }_{100-\mathrm{x}} \mathrm{Zn}_{\mathrm{x}}$ Alloy. Journal of 
Inorganic Non-Metallic Materials, 2, 11-17. http://dx.doi.org/10.4236/ojinm.2012.22002

[2] Elliot, S.R. (1991) Chalcogenide Glasses. In: Zarzycki, J., Ed., Materials Science and Technology, VCH, New York, 375-454.

[3] Hafiz, M.M., El-Shazly, O. and Kinawy, N. (2001) Reversible Phase in $\mathrm{Bi}_{x} \mathrm{Se}_{100-x}$ Chalcogenide Thin Films for Use as Optical Recording Medium. Applied Surface Science, 171, 231-241. http://dx.doi.org/10.1016/S0169-4332(00)00709-1

[4] Popescu, M. (2006) Self-Organization in Amorphous Semiconductors and Chalcogenide Glasses. Journal of Advanced Materials, 8, 2164-2168.

[5] Soltan, A.S., Abu El-Oyoun, M., Abu-Sehly, A.A. and Abdel-Latief, A.Y. (2003) Thermal Annealing Dependence of the Structural, Optical and Electrical Properties of Selenium-Tellurium Films. Materials Chemistry and Physics, 82, 101-106. http://dx.doi.org/10.1016/S0254-0584(03)00184-6

[6] Elliot, S.R. and Steel, A.T. (1987) A Model for the Chemical Modification of Electrical Properties of Chalcogenide Glasses by Bismuth. Journal of Physics C: Solid State Physics, 20, 4335-4357. http://dx.doi.org/10.1088/0022-3719/20/27/012

[7] Schottmiller, J., Tabak, M., Lucovsky, G. and Ward, A. (1970) The Effect of Valency on Transport Properties of in Vitreous Binary Alloys of Selenium. Journal of Non-Crystalline Solids, 4, 80-96. http://dx.doi.org/10.1016/0022-3093(70)90024-4

[8] Minaev, V., Timoshenko, S. and Kalugin, V. (2005) Structural and Phase Transformations in Condensed Selenium. Journal of Optoelectronics and Advanced Materials, 7, 1717-1741.

[9] Ohring, M. (2001) The Material Science of Thin Films. 5th Edition, Academic Press, London.

[10] Born, M. and Wolf, E. (1999) Principles of Optics. 7th Edition, Cambridge University Press, London. http://dx.doi.org/10.1017/CBO9781139644181

[11] Swanepoel, R. (1983) Determination of the Thickness and Optical Constants of Amorphous Silicon. Journal of Physics E: Scientific Instruments, 16, 1214-1218. http://dx.doi.org/10.1088/0022-3735/16/12/023

[12] Barman, J., Sharma, K.C., Sarma, M. and Sarma, K. (2008) Structural and Optical Studies of Chemically Prepared CdS Nanocrystalline Thin Films. Indian Journal of Pure and Applied Physics, 46, 339-343.

[13] Goswami, A. (2005) Thin Film Fundamentals. 5th Edition, New Age International, New Delhi.

[14] Alwan, T.J. (2011) The Influence of Substrate Temperature on Density of States and Optical Properties of $\mathrm{Ge}_{0.2} \mathrm{Te}_{0.8}$ Thin Films. Lebanese Science Journal, 12, 91-100.

[15] Tauc, J. (1974) Amorphous and Liquid Semiconductors. Plenum Press, London \& New York. http://dx.doi.org/10.1007/978-1-4615-8705-7

[16] Shaaban, E.R., Yahia, I.S. and El-Metwally, E.G. (2012) Validity of Swanepoel's Method for Calculating the Optical Constants of Thick Films. Acta Physica Polonica A, 121, 628-635.

[17] Majeed Khan, M.A., Zulfequar, M. and Husain, M. (2003) Optical Investigation of a-Se ${ }_{100-x} \mathrm{Bi}_{\mathrm{x}}$ Alloys. Optical Materials, 22, 21-29. http://dx.doi.org/10.1016/S0925-3467(02)00234-3

[18] Chauhan, R., Tripathi A., Srivastava, A.K. and Srivastava, K.K. (2013) Effect of Swift Heavy Ion Irradiation on Optical and Structural Properties of Amorphous Ge-As-Se Thin Films. Chalcogenide Letters, 10, 63-71.

[19] Ambika and Barman, P.B. (2012) Effect of Bi Addition on the Optical Band Gap of $\mathrm{Se}_{85} \mathrm{Te}_{15}$ Chalcogenide Thin Films. Journal of Non-Oxide Glasses, 3, 19-24.

[20] Mulama, A.A., Mwabora, J.M., Oduor, A.O. and Muiva, C.M. (2014) Optical Properties and Raman Studies of Amorphous Se-Bi Thin Films. The African Review of Physics, 9, 33-37.

[21] Kumar, A., Heera, P., Barman, P.B. and Sharma, R. (2012) Optical Properties of Bi Doped Se-Te Thin Films. Journal of Ovonic Research, 8, 135-146.

[22] Elliot, S.R. (2000) The Physics and Chemistry of Solids. John Wiley \& Sons, Chichester.

[23] Mulama, A.A., Mwabora, J.M., Oduor, A.O., Muiva, C.M. and Muthoka, B. (2014) Investigation of the Effect of Film Thickness on the Optical Properties of Amorphous $\mathrm{Se}_{85-\mathrm{x}} \mathrm{Te}_{15} \mathrm{Sb}_{\mathrm{x}}$ Thin Films. African Journal of Physical Sciences, $\mathbf{1}$, 38-42.

[24] Mansour, B.A., Shaban, H., Gad, S.A., El-Gendy, Y.A. and Salem, A.M. (2010) Effect of Film Thickness, Annealing and Substrate Temperature on the Optical and Electrical Properties of $\mathrm{CuGa}_{0.25} \mathrm{In}_{0.75} \mathrm{Se}_{2}$ Amorphous Thin Films. Journal of Ovonic Research, 6, 13-22.

[25] Muiva, C.M., Sathiaraj, T.S. and Mwabora, J.M. (2012) Chemical Bond Approach to Optical Properties of Some Flash Evaporated $\mathrm{Se}_{100-\mathrm{x}} \mathrm{Sb}_{\mathrm{x}}$ Chalcogenide Alloys. The European Physical Journal of Applied Physics, 59, P1-P7. http://dx.doi.org/10.1051/epjap/2012120082 